\title{
Seminal Vesicle/Coagulating Gland
}

National Cancer Institute

\section{Source}

National Cancer Institute. Seminal Vesicle/Coagulating Gland. NCI Thesaurus. Code

C92216.

A tissue sample that contains a seminal vesicle and coagulating gland. 